\title{
Development Of Website-Based Blended Learning Model For Education Technology Equipment In IAKN Tarutung
}

\author{
Oktober Tua Aritonang \\ otaritonang68@gmail.com \\ Institut Agama Kristen Negeri Tarutung, North Sumatera Indonesia
}

\begin{abstract}
The purpose of the research was to develop a website-assisted blended learning model in Educational Technology that implicated at IAKN Tarutung, North Sumatera regency Indonesia. Developing the new model was based on Borg and Gall development research method with the ADDIE Model instructional design step. Data collection techniques that was used were in the form of literature studies, questionnaire, and test. To determine the practicality of the model, validation was carried out by design and media experts, one to one evaluation, small group evaluation and field trials. The validation results showed that the percentage of practicality of the blended model developed was significantly practical. It was found that the final score of the respondents was the same and was higher than 75 (Minimum completeness criteria), and the average final score of 79.84 is higher than the minimum Mastery Criterion (KKM) of 75. It means that the blended learning model of Educational Technology which was developed, is effective and can improve the ability of students to practice Educational Technology.
\end{abstract}

Keywords: development, website-based blended learning model, educational technology

\section{Introduction}

The rapid development of information and communication technology, has had a considerable influence on the field of education in the digital age of the 21 st century. The effect is a change in learning approach from the classical approach or ordinary face-to-face learning (conventional) to non-classical, meaning that the learning process can occur anywhere, anytime and with anyone without going through face-to-face. Learning resources are no longer just printed books but in the form of e-books (electronic books), video tutorials, video streaming, audio films, multimedia posted on the website so that it can be downloaded easily. The lecture method no longer dominates and students do not only depend on information provided by thelecturer.

Problems or gaps found by researchers in the learning process of the course "Educational Technology Practice" as well as in other courses at the Tarutung State Christian Religion Institute, that the lecture process through face-to-face lecture method causes students to tend to be less enthusiastic about participating in the learning process, interests and independence the learning is still lacking and the level of mastery of lecture material is not optimal, especially in practice materials designing lesson plans, modules and designing multimedia related to computer programs such as Microsoft Power Point which are inserted with video, running text and hyperlinks, and pinacle studio applications. Another obstacle faced is the frequent delay in face-to-face lectures according to schedule due to lecturer lecturers who hold concurrent assignments, while it is difficult to find another time for a substitutemeeting.

So based on the obstacles that have been stated, it is clear that such conditions really require a touch of innovation in the learning process. Ordinary face-to-face learning system needs to be innovated. On this basis the researcher seeks to make a change in learning approach from ordinary face-to-face classical systems to learning with blended learning that combines the process of face-to-face classical learning with e-learning (online learning) with the assistance of websites and to meet those needs it is necessary to develop instructional designs based blended learning. According to Barney Warf (2018) websites are thus where the psychology of the user confronts the structure and content of the Internet. For many organizations (e.g., companies, universities, nonprofits), they are their most visible face to the public [1]. This is what motivated the researchers to design a research development, namely the development of a website-assisted Blended Learning model in the Educational Technology Practice course at IAKNTarutung.

Traditional learning sources of printed teaching materials such as textbooks or modules are integrated with their utilization of digital or electronic learning resources (online) such as websites, text, audio, visuals, multimedia and stored videos digitally through a website or weblog that can be accessed anytime and anywhere. This site also provides space as an online discussion forum that involves all students [2]. According to Harsanto (2014) website is a means of presenting content provided by the owner or manager through the posts sentin the context of e-learning. 
The website is used to deliver lecture reference material, announce something to students, give assignments or practice and conduct discussions online [3].

\section{Method}

This research is a development study that uses a mixed approach. "Mixed methods studies are those that combine qualitative and quantitative approaches into research methodology" [4]. Mixed method can be interpreted research methods that combine qualitative approaches with quantitative.

The process of developing this model is by adapting the ADDIE Instructional development model which includes five main steps and is modified with the Borg \& Gall development research procedure until the fifth step. The instrument used to assess the feasibility of the model (formative evaluation) is a closed questionnaire with 4 answer options. To determine the criteria for the effectiveness of the product being developed, it is done by consulting the acquisition of the student's final grade at the large group test stage against the minimum standard criteria that is complete the value of B (value 75). The model developed is said to be effective if the average value of student learning outcomes $\geq 75$ (CategoryB).

\section{Results}

Results of AnalysisPhase

a. Literature Review Result

Blended learning is a learning pattern that contains an element of mixing (combination) between ordinary and conventional learning with online learning by utilizing computer technology as a medium, in this case with the help of a website. The composition of blended learning applied is $75 / 25$, meaning $75 \%$ of ordinary face-to-face learning, and $25 \%$ of online learning through the website.

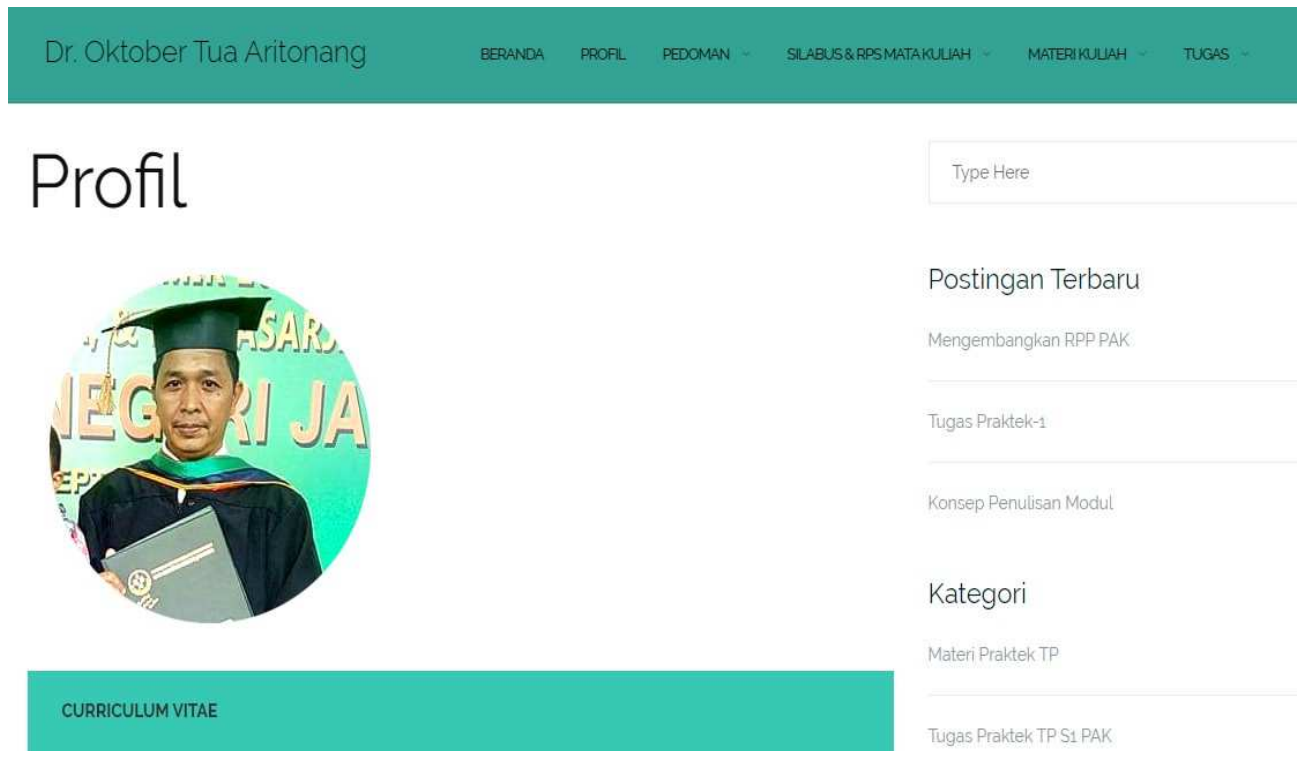

Fig.1. Example of Hompage of Lecturer Web

\section{b. Needs Analysis Result}

Based on a needs assessment conducted through a questionnaire of 25th and 9th Christian Religious Education Study Program students who have taken Education Technology Practice courses as many as 25 people, the information was obtained that $100 \%$ agreed that the supporting lecturers were able to implement blended learning with website assistance in the lecture process of Educational Technology Practices. The reason is that the time allocation is very limited for practice materials and lectures are oftendelayed.

\subsection{Results of the Planning (Design) Phase}

a. Task Analysis 
Based on the analysis of the tasks carried out, it is determined several tasks that must be done by students so that learning objectives are achieved including: developing plans for implementing Christian Religious Education (RPP) learning modules, learning modules and developing multimedia.

b. Write InstructionalObjectives

Based on the instructional analysis carried out, certain instructional objectives are set according to the specified syllabus.

c. Develop Performance Tests

The test used in this research development is a performance test in the form of an assessment rubric of product results developed by students, namely designing lesson plans, learning modules and multimedia.

\section{Results of the DevelopmentPhase}

a. Development of LectureMaterials

The course material developed is adapted to the subjects in the syllabus including: instructional principles and instructional design concepts and models, development of lesson plans and modules.

b. Learning MediaDevelopment

Media developed for student learning materials are examples of video tutorials and multimedia presentations.

c. FormativeEvaluation

The evaluation carried out at this stage starts from the evaluation of design experts and the media, one-on-one evaluations of 3 students and 10 students for small group evaluations. The aim is to assess the feasibility of the initial prototype of the product being developed as well as the shortcomings that need to berevised.

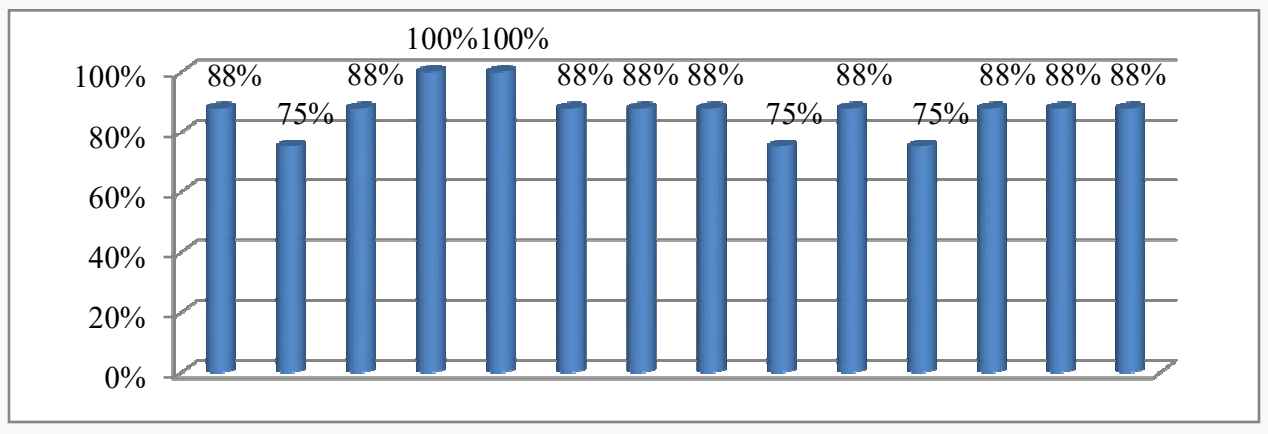

Fig.2. Validity Result Upon The Blended Learning

Overall the average percentage of the feasibility of the model prototype based on the results of the analysis of the design expert assessment questionnaire data is as follows: $87 \%$ of the categories are very feasible, but the appearance of the website homepage, clarity and attractiveness of teaching materials still need to be revised. Based on the feasibility test by media experts the following results were obtained:

Overall the average percentage of the feasibility of the model prototype based on the results of the analysis of the media expert questionnaire data assessment was $92 \%$ very feasible but the website component and the completeness of the material posted still needed to be added. Furthermore, the results of the feasibility test of the blended learning model developed based on the results of the one-on-one test (one to one test) by 3 students can be seen in the following figure:

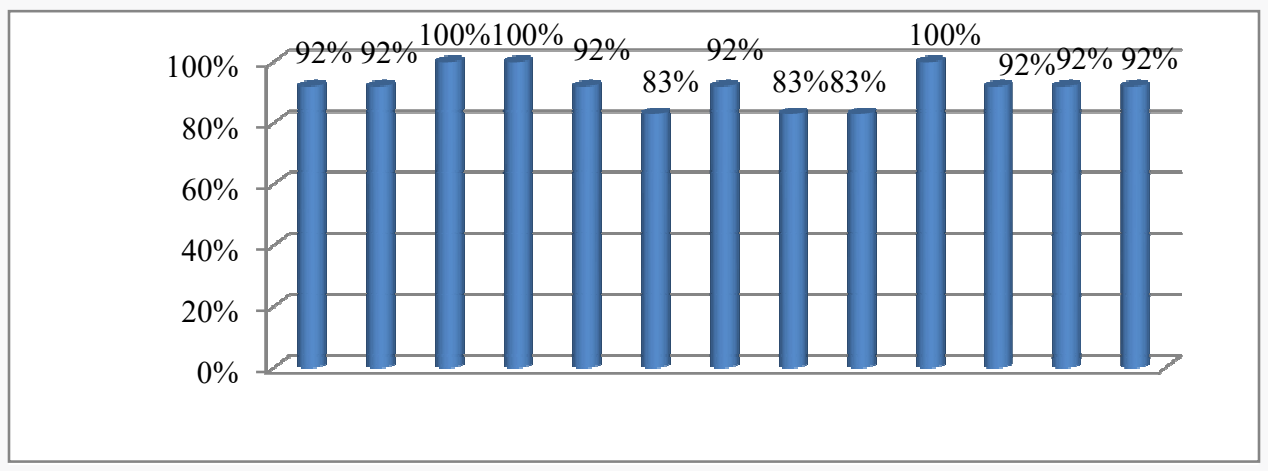

Fig.3. One to One Test Result on Blended Learning Model 
Overall the average percentage of the feasibility of the model based on the analysis of the one-on-one evaluation questionnaire data is $92 \%$ very feasible but aspects of the completeness of the strategy and the attractiveness of teaching materials need to be revised. The next stage is the product feasibility test by a small group of 10 students, the following results are obtained:

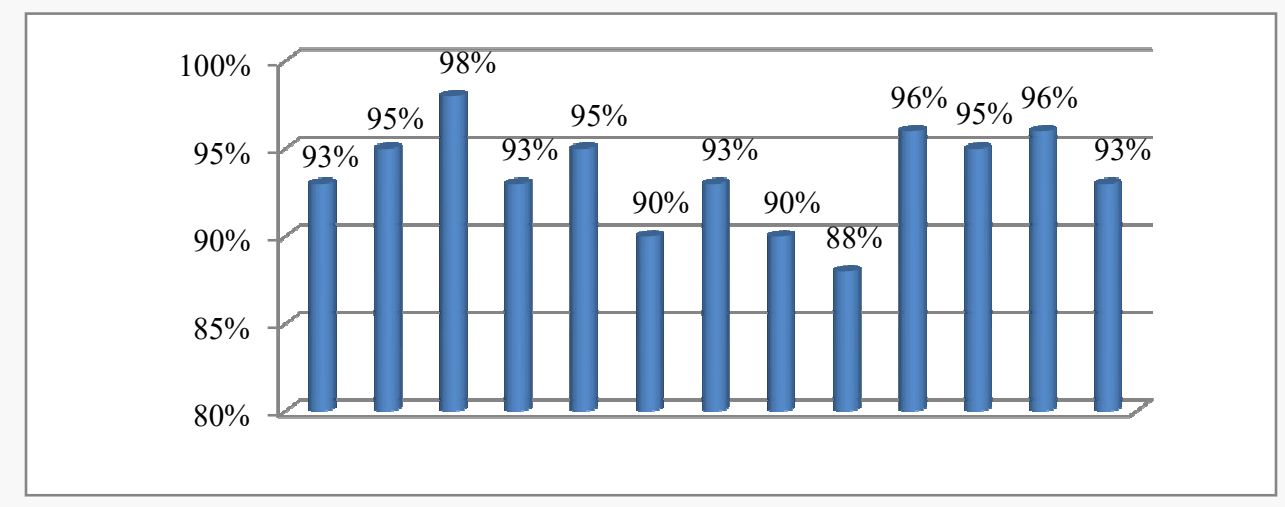

Fig.4. Small Group Test Results on the Blended Learning Model

\section{Results of the Implementation and EvaluationPhase}

After the model is implemented in the actual class followed by 25 students of D group of PAK Study Program, further formative evaluation is carried out, namely field evaluation (limited large groups), the aim is to determine the feasibility of the product being developed and to determine the effectiveness of the model. The percentage of the feasibility of the model based on the results of the field test questionnaire data analysis is $95 \%$ very feasible to use and does not need to be revised. Products are said to be effective if the final student learning outcomes $\geq 75$ (value) Based on the final test conducted, it was found that 24 students scored above 75 (minimum completeness criteria) and 1 student scored 75 the same as KKM. The average overall final test result is $79.84 \geq 75$ exceeded the minimum mastery criterion (KKM), thus the instructional product model of blended learning in the Education Technology Practice course developed has been effective foruse.

\section{Discussion}

The model is a visualization or picture that represents an instructional design process, which includes the main components or stages of a process and its relationship with one another [5]. This can be interpreted that the model is a picture that describes the stages and components involved in the instructional design (development) process and its relationship with oneanother.

According to Benny A.Pribadi (2009) the instructional design model is a picture that can be graphical or a chart of the steps or procedures that must be carried out to create an effective, efficient and elegant learning process [6]. So the instructional design model is a visualization or picture in the form of graphics and charts that represent the main components in the instructional system and their relationship with each other and the procedures that must be carried out to create an efficient, effective and elegant learning process. The function of the model is as a prototype so that it allows developers to produce products asexpected.

There are several instructional design models that are well known and commonly used by learning developers including: Briggs and Wager models, Bela H. Banathy models, Dick and Carey models [7], the AT\&T model [8], and the ADDIE model [9]. Blended learning implies learning patterns that contain elements of mixing or merging between one pattern with another pattern. Curtis J. Bonk \& Charles R. Graham (2006) argues that: "Blended learning systems combine face to face instruction with computer mediated instruction" [10]. Based on studies conducted by Oliver \&Trigwell [3] analyze in more detail the purpose of the combination in blended learning which includes: a mixture of e-learning with traditional learning, a mixture of online learning with face to face, a mixture of learning media, a mixture of context and learning theory. Blended learning is a combination or combination of face-to-face learning (face to face) with e-learning learning (online) by utilizing computer technology as a medium. In the blended learning process, students do not only rely on the material provided by the lecturer, but can look for material from various learning sources through search engines, therefore they are required to learn independently from individual students. According to David Lowe and Martin Gaedke (2005) website is a collection or set of pages that are managed by a particular server [11]. Website is a collection of pages that areused 
to display various information in the form of text, still images or motion pictures, sounds, animated materials and all of them form a related series and each of them is connected with a network of pages [12]. People use website to share information and exchange text, pictures, videos, audio, and software application [13]. The developer adapted the ADDIE Instructional development model in developing this website-assisted blended learning model, which includes 5 main steps and is modified with development research procedures according to Borg \& Gall[14].

\section{Conclusion}

The process of developing a blended learning model in the Educational Technology Practice course at Tarutung IAKN website-assisted starts from the initial prototype to the final model which is carried out in several steps by adapting the ADDIE design model that includes five steps and combined with the Borg \& Gall development research procedures until the fifth step. The steps of implementing the blended learning model in the Education Technology Practice course are carried out by preparing the learning environment and respondent students who will be included in the application of the instructional product beingdeveloped.

Based on the results of the study it can be concluded that the percentage of feasibility of products developed according to design experts $87 \%$, $92 \%$ media experts, $92 \%$ one-on-one test, $94 \%$ small group test and $95 \%$ field test are all in the very feasible category. And based on the results of the final tests conducted, average acquisition of the final value of respondents is $79.89 \geq 75$ (KKM) this means that the developed blended learning model has been effective. It is time for the lecturers at IAKN Tarutung to apply the blended learning model to the courses they teach, because this model has been proven effective and can overcome the weaknesses of face-to-face learning such as the problem of time constraints in the classroom or the delayed lectures, in addition to this model students are trained to learn independent, responsible and collaborate with one another. Students at IAKN Tarutung are advised to prepare themselves to participate in the development of digital technology to support the innovation of the learning process conducted by lecturers supporting the courses.

\section{References}

[1] Warf, Barney.: The SAGE Encyclopedia of The Internet. UK: SAGE Publication Ltd.p.956(2018)

[2] Yaumi, Muhammad.: Media \& Learning Technology. Jakarta: Prenadamedia Group. pp.207-209(2018)

[3] Harsanto, Budi.: Learning Innovation in the Digital Age. Bandung: Unpad Press. p.23 (2014)

[4] Teddle, Charles \& Abbas Tashakkori.: Hanbook of Mixed Methods in Social \& Behavioral Research. USA: SAGE Publications, Ins. p.352(2003)

[5] Management Resources Information Resources.: Instructional Design: Concepts, Methodologies, Tools and Applications. USA: IGI Global. p.81(2011)

[6] Pribadi, Benny A.: Learning System Design Model. Jakarta: Dian Rakyat. p.86(2009)

[7] Degeng, I NyomanSudana and MiekeO.Mandagi.: Learning Model and Design. Malang East Java: CV.Thousand Stars.pp.73-76(2019)

[8] Supaman, M. Atwi.: Guidance for Teacher \& Educational Innovators: Modern Instructional Design. Jakarta: Erlangga. p.107(2012)

[9] Branch, Robert Maribe.: Instructional Design: The ADDIE Approach. New York: Springer Science. P.2(2009)

[10] Graham, R.Charles and Curtis J. Bonk.: The Handbook of Blended Learning. USA: John Wiley \& Sons, Inc. p.5 (2006)

[11] Gaedke, Martin and David Lowe.: Web Engineering. Germany: Springer-Verlag Berlin. P.124(2005)

[12] Hidayat, Rahmat.: A Practical Way to Build a Free Website. Jakarta: PT.Elex Media Komputindo. p.2(2010)

[13] Poolos, J.: Digital and Information Literacy: Designing, Building, and Maintaining Websites. New York: The Rosen Publishing Group, Inc. p.8(2018)

[14] R. Borg, Walter \& Meredith Damien Gall.: Educational Research An Introduction. New York: Longman Inc. pp.775-776 (1983) 